- $\quad$ presentations of different modeling and computer simulations, density standards

- $\quad$ up-to-date references to mid-2013

The authors will adhere to the nomenclature and symbols of the IUPAC "Green Book" and any deviations will be defined and explained.

For more information, or if you are interested in being part of this Task Group and can contribute something new to the subject, please contact Task Group Chair Trevor Letcher <trevor@letcher.eclipse.co.uk〉.

www.iupac.org/project/2012-038-1-100

\section{Toward Higher Quality Chemistry Teacher In-Service Training in Croatia}

In November 2010, the 1st Croatian Workshop on Chemical Education, held in the town of Split, focused on the quality of in-service teacher training, inquirybased learning, and learner-oriented teaching strategies. The workshop was the outcome of a CCE Flying Chemists program intended to develop the process of in-service training of chemistry teachers in Croatia and the region and to catalyze the dissemination process of in-service experiences among neighboring countries.

The program of activities in Croatia followed a model used successfully by the Flying Chemists Program in the Philippines, India, and Sri Lanka, namely bringing together at the national level a critical mass of chemistry educators to improve chemistry education, facilitated by external resource persons with expertise in areas targeted by the country. The Croatian Flying Chemists Program was a partnership among the Ministry of Science, Education, and Sport; the Croatian Education and Teacher Training Agency; and the Croatian Chemical Society. The first workshop had 120 participants from around Croatia and a few from the neighboring countries of Macedonia and Bosnia, who came together to identify ways to strengthen chemistry education at the primary and secondary levels.

The 2nd Croatian workshop on Chemical Education was held in Split, 8-11 November 2012. Despite having a pronounced national prefix, the Croatian Workshop on Chemical Education was organized for an international audience of teachers to primarily discuss problems being regularly encountered in learning and teaching of chemistry at all levels of education. The 2nd CWCE was devoted to the following topics:

- Teaching Chemistry: guided-inquiry and studentoriented learning
- Communication: the "professional language" vs. the mind of the non-expert

- $\quad$ Research in Chemical Education: what to research in chemical education and why?

- The Interdisciplinary Attack: to the mathematics, physics, biology .... and back

- Microscale and Green Chemistry: implementation in the classroom.

In summary, the first steps of the project have been a success, the main short-terms goals of the project have been accomplished, and good ground is now in place to sustain interest and development in chemical education in the region.

For more information, contact Task Group Chair Nenad Judaš (University of Zagreb) <judas@chem.pmf.hr>.

www.iupac.org/project/2009-055-1-050

\section{Guidelines for Multinational Calls for Research Cooperation}

In 2009, the first Transnational Call for Proposals in Polymer Chemistry, an IUPAC pilot call backed by several leading funding organizations, was announced and managed by an IUPAC call secretariat together with a call oversight committee from the IUPAC Polymer Division. The goal of this pilot call was to establish an efficient transnational funding program in chemistry, to transcend national/continental boundaries, to allow for minimal bureaucracy for the applicants, and to establish best practices for future calls of this type.

Teams of three or more principal investigators from three different participating nations were eligible to submit a single research proposal that underwent a single common scientific review and received a single funding decision. For each successful proposal, the individual applicants received funding from their respective national participating agency. Supporting this call were the IUPAC Polymer Division and seven national funding organizations that agreed to participate.

This call had a tremendous resonance: 35 letters of intent were received out of which 30 were approved; 28 full proposals were submitted out of which 7 were selected for funding (see details at www.iupac.org/ polyedu/DivIVCall).

The task of monitoring the call and establishing best-practice guidelines was performed by a team consisting of IUPAC members and representatives of participating funding agencies in an IUPAC project. 